\title{
DEPENDÊNCIA MICORRÍZICA DA LEGUMINOSA Mimosa artemisiana HERINGER \& PAULA
}

\author{
Andréa Hentz de Mello할 Eliana Maria Ribeiro da Silva²; Orivaldo José Saggin Júnior². \\ ${ }^{1}$ Professora, Doutora da Faculdade de Ciências Agrárias, Universidade Federal do Pará - \\ Campus de Marabá. Marabá, Pará, Brasil. andreahentz@ufpa.br \\ ${ }^{2}$ Pesquisador da Embrapa Agrobiologia, Seropédica, Rio de Janeiro, Brasil.
}

RESUMO: Este trabalho teve como objetivo avaliar o grau de dependência micorrízica de Mimosa artemisiana. As sementes foram inoculadas com rizóbium e Glomus etunicatum Becker \& Gerdemann em diferentes níveis de fósforo (P0 disponível (1, 5, 32, 84 e $240 \mathrm{mg} / \mathrm{kg}$ ) no solo. As plantas micorrizadas apresentaram curva típica com redução de crescimento na maior dose de $\mathrm{P}$ em relação às não inoculadas, as quais apresentaram resposta linear ao $\mathrm{P}$ aplicado. As maiores respostas à inoculação de Glomus etunicatum foram observadas com P disponível entre 32 e 84 $\mathrm{mg} / \mathrm{kg}$. As plantas deixaram de responder à inoculação com $\mathrm{P}$ disponível estimado de $187 \mathrm{mg} / \mathrm{kg}$. Conclui-se que a dependência micorrízica de Mimosa artemisiana é intermediária por deixar de responder aos FMAs em níveis altos de $\mathrm{P}$ disponível.

PALAVRAS-CHAVE: fósforo, Glomus etunicatum, inoculação.

\section{MYCORRHIZAL DEPENDENCY OF THE LEGUME Mimosa artemisiana HERINGER \& PAULA}

\begin{abstract}
This study aimed to evaluate the degree for mycorrhizal dependency of Mimosa artemisiana. The seeds were innoculated with rhizobium and arbuscular mycorrhizal fungi Glomus etunicatum Becker \& Gerdemann in level the P disponible $(1,5,32,84$ e $240 \mathrm{mg} / \mathrm{kg})$ extract Mehlich I. Mycorrhized plants presented a typical curve, reducing growling in the greater $\mathrm{P}$ dose in relatives to the non-innoculated, which presented a linear response to $\mathrm{P}$. The major responses to Glomus etunicatum innoculation were observed with P available between 32 and 84 $\mathrm{mg} / \mathrm{kg}$. The plants clased to responde innoculation when P available mycorrhizal dependency this Mimosa artemisiana is intermediate because it ceases responding to AMFs in high levels of $\mathrm{P}$ available.
\end{abstract}

KEY-WORDS: inoculation, Glomus etunicatum, phosphorus.

\section{INTRODUÇÃO}

Pouco se conhece das exigências nutricionais das espécies nativas e de suas estratégias para obtenção de nutrientes como a formação de simbiose mutualista entre suas raízes e os fungos do filo Glomeromycota, as 
quais são denominadas micorrizas arbusculares. Estas simbioses são de grande importância na estruturação das comunidades vegetais e, certamente, no reflorestamento de áreas degradadas. $\mathrm{Na}$ maioria das plantas vasculares, esta simbiose favorece sua nutrição mineral, principalmente pelo aumento da absorção de nutrientes pouco móveis no solo, como o fósforo, e maior tolerância a estresses, como déficit hídrico, compactação do solo, altas temperaturas, presença de elementos tóxicos e ataques de pragas e patógenos do sistema radicular (MOREIRA; SIQUEIRA, 2002).

As diferentes espécies de plantas exibem diferenças na suscetibilidade à colonização micorrízica e no grau de dependência aos fungos micorrízicos. A dependência micorrízica (DM) é uma característica própria de cada espécie vegetal e varia com o seu estado fisiológico, com sua exigência nutricional e com sua capacidade ou estratégia de obtenção de nutrientes na ausência de micorrizas (SIQUEIRA; SAGGIN JÚNIOR, 2001).

A DM é um dos fatores responsáveis pela adaptação e competitividade das espécies vegetais no ecossistema. Por isto, é considerada capaz de influenciar a participação das espécies em grupos ecológicos de sucessão florestal (JANOS, 1980), podendo ter papel importante no estabelecimento da flora arbórea e na estruturação das populações dentro das comunidades vegetais de matas regeneradas (SAGGIN JÚNIOR, 1997).

Plantas com baixa DM não necessitam de fungos micorrízicos arbusculares (FMAs) para se nutrirem quando as condições de fertilidade são boas, com níveis altos de P no solo (HABTE; MANJUNATH, 1991). Neste caso, a planta pode ter seu crescimento reduzido em relação àquela que não tenha FMAs. Entretanto, plantas com alta DM podem apresentar respostas à presença de FMAs até com altos níveis de $\mathrm{P}$ disponível no solo (SIQUEIRA; SAGGIN JÚNIOR, 2001).

Para avaliar a DM das plantas é necessário observar as respostas à inoculação com FMAs em pelo menos dois distintos níveis de $\mathrm{P}$ na solução do solo. Habte e Manjunath (1991) propuseram que estes níveis de $\mathrm{P}$ fossem $0,02 \mathrm{mg} . \mathrm{L}^{-1}$ (concentração ótima para o funcionamento da simbiose) e $0,2 \mathrm{mg} . \mathrm{L}^{-1}$ (concentração na qual a maioria das culturas produz $95 \%$ da produtividade máxima).

A DM também pode ser observada plotando-se o crescimento da planta em 
função de níveis crescentes de disponibilidade de P (JANOS, 1988). Neste caso a DM seria indicada pelo nível de $\mathrm{P}$ até o qual as plantas não micorrizadas não aumentem significativamente $\mathrm{o}$ seu crescimento $(\mathrm{T})$ ou pelo nível de fósforo acima do qual as plantas não micorrizadas não cresçam diferentemente das micorrizadas $\left(\mathrm{T}^{\prime}\right)$.

Desta forma o conhecimento da DM das espécies arbóreas pode definir estratégias de reflorestamento, particularmente em ambientes degradados, onde plantas dependentes não cresceriam sem a inoculação com um fungo micorrízico arbuscular eficiente.

\section{MATERIAL E MÉTODOS}

$\mathrm{O}$ experimento foi conduzido em casa de vegetação, em copos plásticos de 700 mL de capacidade, com um tubete acoplado no fundo, totalizando a capacidade de $1000 \mathrm{~mL}$ de substrato.

O substrato foi uma amostra de um Latossolo Vermelho, textura argilosa, coletado da camada de $0-15 \mathrm{~cm}$, em uma área degradada por empréstimo, utilizada para obras de ampliação da Rodovia RJ 141 que liga Resende à Visconde de Mauá-RJ, pertencente ao Campo de Instrução da
Academia Militar das Agulhas Negras. A área localiza-se na encosta da Serrinha do Alambari a $22^{\circ} 22^{\prime} 37^{\prime \prime}$ de Latitude Sul e $44^{\circ} 30^{\prime} 13$ " de Longitude Oeste, a $550 \mathrm{~m}$ de altitude.

O solo foi passado em peneira de $5 \mathrm{~mm}$ e colocado em cubas contendo $4 \mathrm{Kg}$ de solo. Foi umedecido e autoclavado, permanecendo na autoclave à temperatura de $120^{\circ} \mathrm{C}$ e pressão de 1 atm por duas horas, repetindo o processo por mais duas vezes, com intervalo de 2 dias, quando apresentou as seguintes características químicas determinadas conforme metodologias descritas pela Empresa Brasileira de Pesquisa Agropecuária (1979) : $\mathrm{pH}=4,9 ; \mathrm{Al}=0,5$ $\mathrm{cmol}_{\mathrm{C}} / \mathrm{dm}^{3} ; \mathrm{Ca}+\mathrm{Mg}=0,5 \mathrm{cmol}_{\mathrm{d}} / \mathrm{dm}^{3} ; \mathrm{P}=$ $1 \mathrm{mg} / \mathrm{dm}^{3}$.

Sementes de Mimosa artemisiana Heringer \& Paula, foram escarificadas com $\mathrm{H}_{2} \mathrm{SO}_{4}$ por 3 minutos, para a quebra da dormência, e após lavagem foram inoculadas com rizóbio das estirpes BR 3462 e BR 3609 crescidas em meio semi-sólido descrito por Vicent (1970) e usando turfa esterilizada como veículo antes de serem semeadas diretamente nos recipientes contendo o solo.

Avaliou-se a dependência micorrízica da Mimosa artemisiana, baseada na sua resposta em crescimento, à inoculação com 
Glomus etunicatum em diferentes níveis de fósforo no solo.

O delineamento experimental adotado foi parcelas subdivididas em esquema fatorial $2 \times 5$, constando de dois tratamentos de inoculação de FMA, sendo com ou sem inoculação (parcelas) e 5 doses de $\mathrm{P}$ (subparcelas), com 6 repetições. As doses de $\mathrm{P}$ foram $0,50,100,500$ e $1000 \mathrm{mg} \mathrm{P} / \mathrm{kg}$ de solo, e foram definidas baseadas na determinação do fósforo remanescente (Alvarez et al., 1983). O solo possuía $\mathrm{P}$ remanescente de $1,4 \mathrm{mg} / \mathrm{Kg}$, o que significa possuir alta capacidade de fixação de $P$.

Antes do plantio, aplicou-se em cada vaso solução de $\mathrm{KH}_{2} \mathrm{PO}_{4}$ com as doses descritas acima, sendo em seguida o solo cuidadosamente homogeneizado. O nível de $\mathrm{K}$ nos diferentes tratamentos de $\mathrm{P}$ foi equilibrado, aplicando-se níveis complementares de solução de KCL junto com a solução de $\mathrm{KH}_{2} \mathrm{PO}_{4}$. O P disponível no solo, determinado pelo extrator de Mehlich I pelo Laboratório de Análise de Solo da Embrapa Agrobiologia, era de 1; 5; 32; 84 e $240 \mathrm{mg} / \mathrm{dm}^{3}$ para as concentrações de $0 ; 50 ; 100 ; 500$ e $1000 \mathrm{mg} \mathrm{P} / \mathrm{kg}$ de solo, respectivamente. Houve boa relação entre o $\mathrm{P}$ aplicado e o P disponível no solo (Figura $1)$.

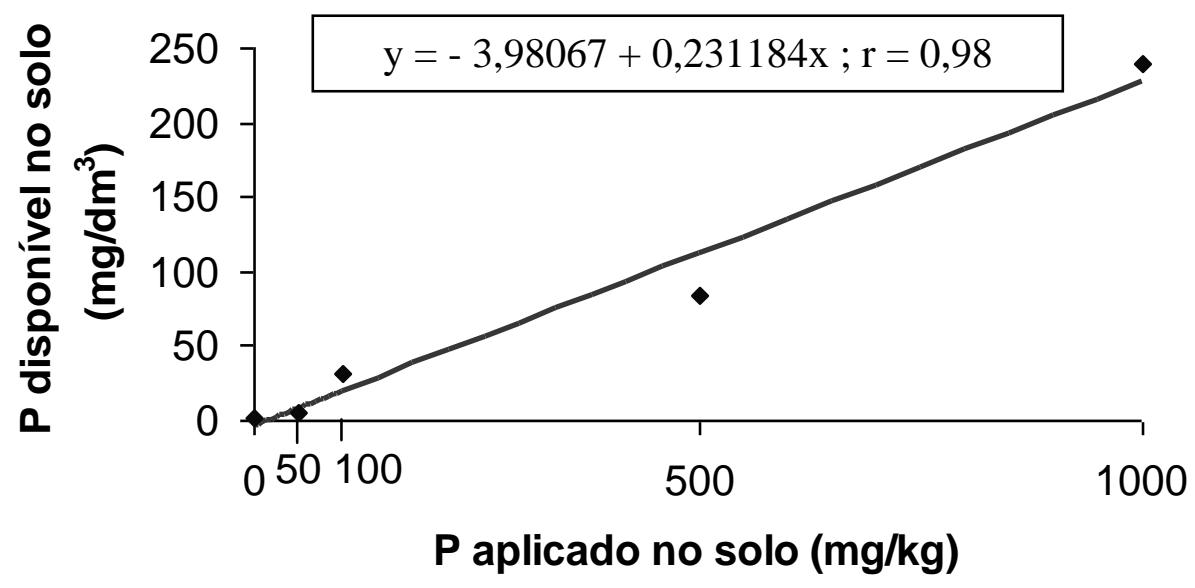

Figura 1. Relação entre P aplicado e P disponível no solo pelo extrator Mehlich I. 
Cada vaso, em um orifício de $1 \mathrm{~cm}$, recebeu 3 sementes da Mimosa artemisiana inoculadas com rizóbio e cerca de 90 esporos do fungo micorrízico arbuscular Glomus etunicatum pipetados sobre as sementes. Após a cobertura dos inoculantes e sementes com uma fina camada de solo, cada vaso foi irrigado com $25 \mathrm{~mL}$ de solução nutritiva, aplicando-se por vaso, $1000 \mathrm{mg}$ de $\mathrm{Ca}$ na forma de $\mathrm{CaSO}_{4} ; 35 \mathrm{mg}$ de $\mathrm{N}$ na forma de $\mathrm{NH}_{4} \mathrm{NO}_{3} ; 200 \mathrm{mg}$ de $\mathrm{Mg}$ na forma de $\mathrm{MgSO}_{4} 7 \mathrm{H}_{2} \mathrm{O} ; 10 \mathrm{mg}$ de $\mathrm{Zn}$ na forma de $\mathrm{ZnSO}_{4} \cdot 7 \mathrm{H}_{2} \mathrm{O} ; 10 \mathrm{mg}$ de $\mathrm{B}$ na forma de $\mathrm{H}_{3} \mathrm{BO}_{3} ; 5 \mathrm{mg}$ de $\mathrm{Cu}$ na forma de $\mathrm{CuSO}_{4} .5 \mathrm{H}_{2} \mathrm{O} ; 0,5 \mathrm{mg}$ de $\mathrm{Mo}$ na forma $\mathrm{Na}_{2} \mathrm{MoO}_{4} \cdot 2 \mathrm{H}_{2} \mathrm{O}$. Esta adubação foi repetida quinzenalmente durante a condução do experimento. Aos 30 dias após a germinação foi realizado um desbaste, deixando uma planta por vaso. As irrigações foram diárias, de modo a manter a umidade próxima a $70 \%$ da capacidade de campo.

Durante o cultivo aos 50, 80 e 110 dias, a Mimosa artemisiana foi avaliada quanto ao crescimento em altura. Aos 140 dias após a germinação, foi colhida e avaliada quanto à altura, massa da parte aérea fresca e seca, densidade de esporos no solo, número de nódulos, teores de nutrientes na parte aérea e colonização micorrízica.
Para o clareamento e coloração das raízes foi utilizada a metodologia de Koske e Gemma (1989), e Grace e Stribley (1991). A colonização micorrízica das raízes, foi avaliada pelo método da interseção em placa quadriculada, de Giovanetti e Mosse (1980), adaptado à partir do método de medida de comprimento de raízes de Newman (1966). Para a extração dos esporos em $50 \mathrm{~mL}$ de solo, foi utilizada a técnica de peneiramento úmido (GERDEMANN; NICOLSON, 1963), com posterior centrifugação em água e sacarose a 40\% (JENKINS, 1964). O número de esporos no solo foi determinado pela contagem dos esporos em microscópio estereoscópico.

$\mathrm{O}$ material da parte aérea foi seco a $65^{\circ}$ C em estufa com circulação de ar, e pesado até atingir massa constante. Foi então moído e digerido com extrator nitro-perclórico (2:1) para extração de $\mathrm{P}, \mathrm{K}, \mathrm{Ca}$ e $\mathrm{Mg}$ e extrator sulfúrico para extração de N (SILVA, 1999; LOUREIRO; BODDEY, 1986). Os teores de $\mathrm{P}$ foram determinados por colorimetria, $\mathrm{K}$ por fotometria de chama e $\mathrm{Ca}$ e $\mathrm{Mg}$ por espectofotometria de absorção atômica (SILVA, 1999), e o $\mathrm{N}$ pelo método de Kjeldahl modificado (LOUREIRO; BODDY, 1986).

Agroecossistemas, v. 4, n. 2, p. 67-78, 2012 
Os dados foram testados quanto a sua normalidade e submetidos à análise de variância, teste de médias (Tukey 5\%) e regressão, utilizando-se dos procedimentos disponíveis no programa Sisvar (FERREIRA, 1998).

\section{RESULTADOS E DISCUSSÃO}

Ao avaliar a dependência micorrízica da Mimosa artemisiana, inoculada com
Glomus etunicatum em diferentes níveis de fósforo, verificou-se que houve efeito acentuado tanto da inoculação quanto das doses de $\mathrm{P}$ aplicadas. A interação entre os fatores foi significativa na maioria das variáveis avaliadas. A altura da Mimosa artemisiana em diferentes épocas após a semeadura são apresentados na Tabela 1 .

Tabela 1. Altura de mudas de Mimosa artemisiana inoculadas (In) ou não inoculadas (Ni) com Glomus etunicatum aos 50, 80 e 110 dias após a germinação (Média de 6 repetições).

\begin{tabular}{|c|c|c|c|c|c|c|}
\hline Doses de P & 50 dias & & 80 dias & & 10 dias & \\
\hline $\mathrm{mg} / \mathrm{kg}$ & In & $\mathrm{Ni}$ & In & $\mathrm{Ni}$ & In & $\mathrm{Ni}$ \\
\hline 0 & $0,92 \mathrm{a}$ & $1,00 \mathrm{a}$ & $2,00 \mathrm{a}$ & $1,33 \mathrm{a}$ & $3,17 \mathrm{a}$ & $2,00 \mathrm{a}$ \\
\hline 50 & $1,50 \mathrm{a}$ & $1,33 \mathrm{a}$ & $3,33 \mathrm{a}$ & $2,33 \mathrm{a}$ & $6,75 \mathrm{a}$ & $3,12 \mathrm{a}$ \\
\hline 100 & $2,00 \mathrm{a}$ & $1,67 \mathrm{a}$ & $3,67 \mathrm{a}$ & $2,67 \mathrm{a}$ & $8,75 \mathrm{a}$ & $3,25 \mathrm{~b}$ \\
\hline 500 & $4,17 \mathrm{a}$ & $1,17 \mathrm{~b}$ & $4,75 \mathrm{a}$ & $2,92 \mathrm{~b}$ & $11,08 \mathrm{a}$ & $8,08 \mathrm{a}$ \\
\hline 1000 & $5,50 \mathrm{a}$ & $2,17 \mathrm{~b}$ & $2,17 \mathrm{a}$ & $2,58 \mathrm{a}$ & $14,67 \mathrm{a}$ & $13,42 \mathrm{a}$ \\
\hline $\mathrm{R}^{2}$ & 0,96 & - & 0,91 & - & 0,98 & 1,00 \\
\hline Ajuste & Linear** & Sem ajuste & Quadrática ${ }^{* *}$ & Sem ajuste & Raiz quadrada** & Linear $^{* *}$ \\
\hline
\end{tabular}

Verificou-se que aos 50 dias após a germinação houve um efeito da inoculação de aumentar a altura das plantas nas doses 500 e $1000 \mathrm{mg}$ P/kg. Aos 80 dias este efeito foi verificado apenas na dose $500 \mathrm{mg} \mathrm{P} / \mathrm{kg}$ e aos 110 dias na dose de $100 \mathrm{mg} \mathrm{P} / \mathrm{kg}$. As doses de $\mathrm{P}$ também afetaram a altura. As plantas inoculadas apresentaram ajuste quadrático e raiz quadrada aos 50, 80 e 110 dias, respectivamente.

As plantas não inoculadas inicialmente apresentaram pouca resposta ao $\mathrm{P}$, não apresentando ajustes para altura aos 50 dias e 80 dias. Aos 110 dias responderam linearmente a aplicação de $\mathrm{P}$ no solo. A resposta em altura das plantas inoculadas e 
não inoculadas aos 110 dias é apresentada na Figura 2.

As plantas micorrizadas apresentaram uma resposta raiz quadrada típica (SAGGIN JÚNIOR; SIQUEIRA, 1994) com redução de altura em relação às plantas não inoculadas na dose mais alta de $\mathrm{P}$. O ponto máximo da curva ocorreu entre as doses 100 e $500 \mathrm{mg} / \mathrm{kg}$ de $\mathrm{P}$, o que em termos de $\mathrm{P}$ disponível por Mehlich I corresponde entre 32 e $84 \mathrm{mg} / \mathrm{kg}$ de solo. As plantas sem micorrizas responderam linearmente à aplicação de $\mathrm{P}$ no solo, apresentando também comportamento típico de plantas não inoculadas (SAGGIN JÚNIOR; SIQUEIRA, 1994). Verifica-se benefícios acentuados da inoculação nas doses de 50, 100 e $500 \mathrm{mg} \mathrm{P} / \mathrm{kg}$, confirmados significativamente pelo teste de Tukey $1 \%$ (não apresentado). O ponto de cruzamento entre as curvas, que equivale ao ponto $T^{\prime}$ de JANOS (1988) é de $823 \mathrm{mg} \mathrm{P} / \mathrm{kg}$.

Este comportamento foi verificado também em outras variáveis de crescimento da planta, como massa da parte aérea fresca e seca e número de folhas. A massa da parte aérea seca é apresentada na Figura 3.

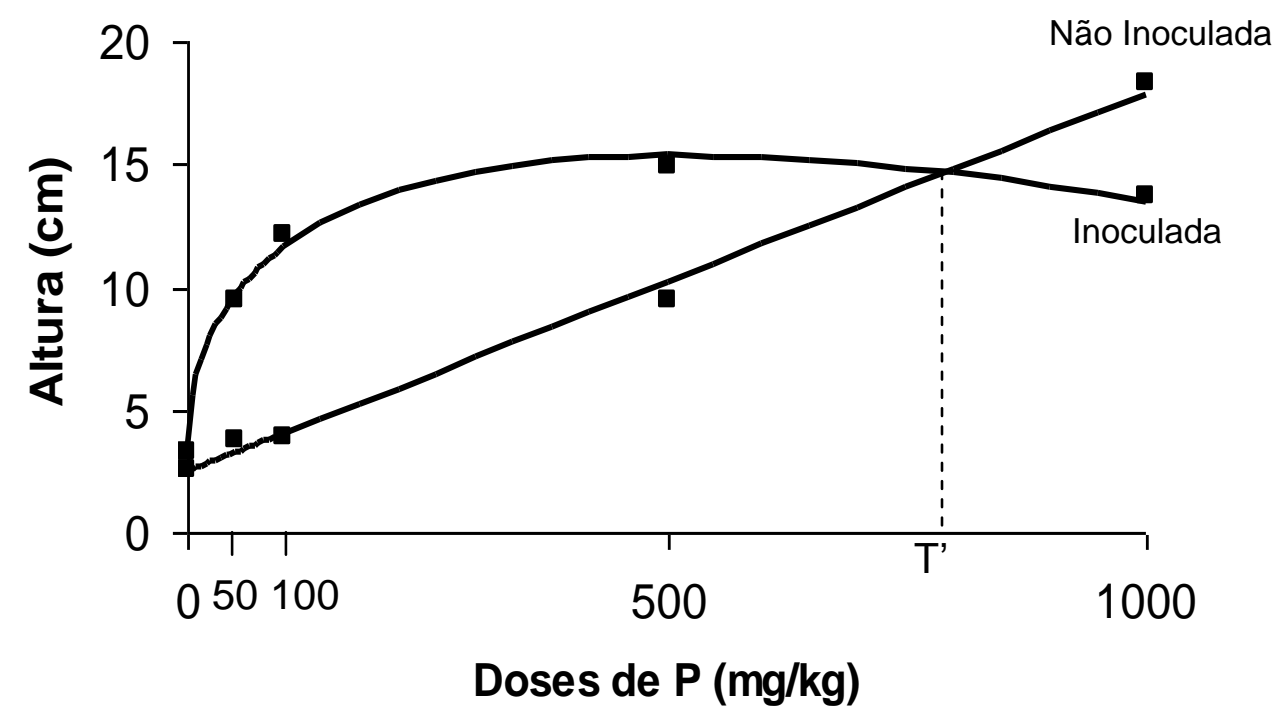

Figura 2. Altura das mudas da Mimosa artemisiana aos 110 dias após a germinação inoculadas ou não com Glomus etunicatum em diferentes doses de $\mathrm{P}$ no solo. Inoculada: $\mathrm{Y}=3,34-$ $0,023 \mathrm{X}+1,055 \mathrm{X}^{0,5} ; \mathrm{R}^{2}=0,99$, Não inoculada: $\mathrm{Y}=2,12+0,012 \mathrm{X} ; \mathrm{R}^{2}=1,00$. Ambos os ajustes são significativos $(\mathrm{P} \leq 0,01)$. 


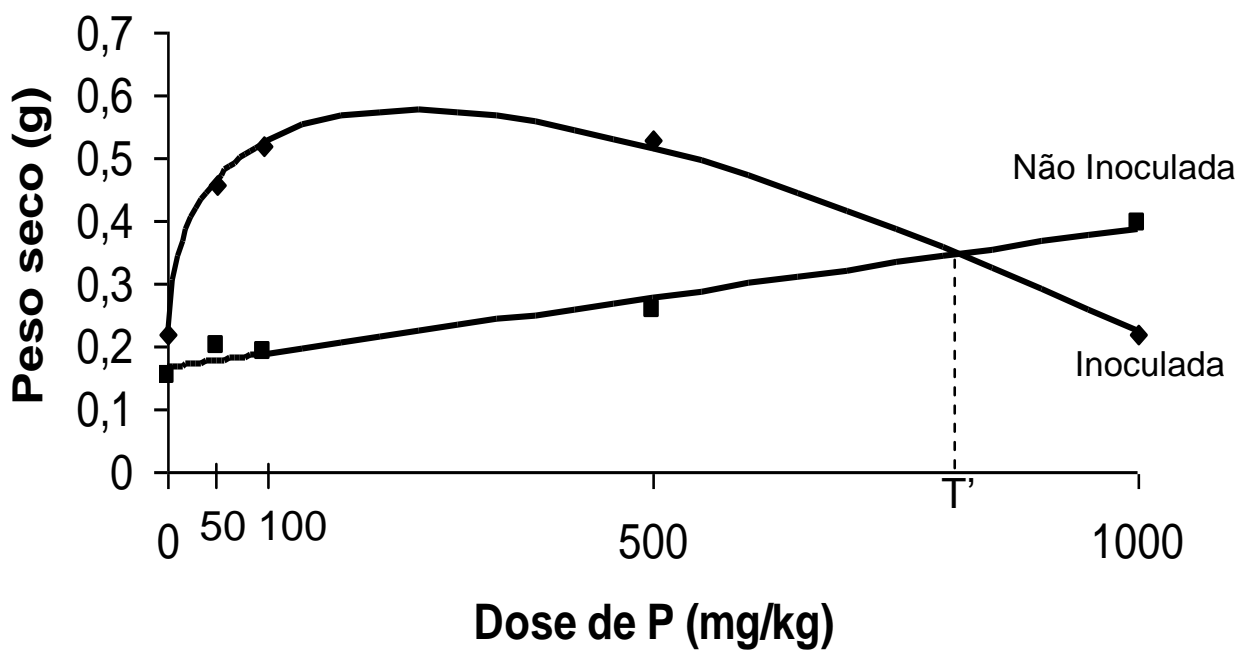

Figura 3. Massa da parte aérea seca da Mimosa artemisiana aos 110 dias após a germinação inoculadas ou não com Glomus etunicatum em diferentes doses de $\mathrm{P}$ no solo. Inoculada: $\mathrm{Y}=$ $0,211-0,00143 X+0,0456 X^{0,5} ; R^{2}=0,99$. Não inoculada: $Y=0,16506+0,000222900 X ; R^{2}=0,97$. Ambos os ajustes são significativos $(\mathrm{P} \leq 0,05)$.

A variação desta variável em função da dose de $\mathrm{P}$ foi mais intensa que da altura das plantas, apresentando o ponto de máxima resposta das plantas micorrizadas em $260 \mathrm{mg}$ $\mathrm{P} / \mathrm{kg}$, o que estima-se pela figura 2 estar num nível de P disponível por Mehlich I em torno de $56 \mathrm{mg} / \mathrm{kg}$. O ponto T' (JANOS, 1988), foi $825 \mathrm{mg} / \mathrm{kg}$ de $\mathrm{P}$, portanto muito próximo do obtido para altura.

A colonização micorrízica aos 110 dias após a germinação não foi afetada pelos níveis de $\mathrm{P}$ (Tabela 2). As plantas micorrizadas apresentaram uma colonização média de 47,5\%. Não houve colonização micorrízica nas plantas não inoculadas confirmando o sucesso do controle de contaminação feito em casa de vegetação.

A densidade de esporos foi bastante afetada pelas doses de $\mathrm{P}$ (Tabela 2), entretanto, não se conseguiu um ajuste de regressão para seu comportamento, sendo que foi maior na dose de $100 \mathrm{mg} \mathrm{P} / \mathrm{kg}$ e menor na dose de $0 \mathrm{mg} \mathrm{P} / \mathrm{kg}$. Também não se verificou esporulação de FMAs nas plantas não micorrizadas.

A nodulação foi beneficiada pela micorrização nas doses de 100 e 1000 mg $\mathrm{P} / \mathrm{kg}$, sendo influenciada pela elevação do $\mathrm{P}$ no solo, havendo tendência de comportamento linear apesar dos ajustes 
significativos com coeficiente de determinação pouco abaixo de 0,80 .

Os teores de nutrientes na parte aérea da Mimosa artemisiana revelam que a inoculação de Glomus etunicatum foi eficiente em promover benefício nutricional nos teores de N, P e K (Tabela 3).

Os teores de $\mathrm{N}$ foram aumentados pela inoculação nas menores doses de $\mathrm{P}(0,50$ e $100 \mathrm{mg} / \mathrm{kg}$ ). Os de $\mathrm{K}$ também foram beneficiados pela inoculação em praticamente todas as doses de $\mathrm{P}$, exceto na dose $1000 \mathrm{mg} / \mathrm{kg}$, apesar de nesta dose a tendência foi a de ter o mesmo comportamento.
As respostas da Mimosa artemisiana à inoculação em altura (Tabela 1) indicam que esta espécie pode apresentar maior dependência a estes fungos nas fases iniciais de crescimento, visto que aos 50 e 80 dias as resposta à inoculação foram observadas nas doses mais elevadas de $\mathrm{P}$ e com aumento da idade da planta as respostas à micorrização passaram a ser observadas apenas nas doses intermediárias de P. Este tipo de comportamento também ocorre com o cafeeiro que apresenta maior dependência aos fungos micorrízicos arbusculares na fase de mudas do que na fase adulta (SAGGIN JÚNIOR; SIQUEIRA, 1999).

Tabela 2. Colonização micorrízica, número de esporos e número de nódulos em mudas de Mimosa artemisiana inoculadas (In) ou não inoculadas (Ni) com Glomus etunicatum aos 110 dias após a germinação (Média de 6 repetições).

\begin{tabular}{|c|c|c|c|c|c|c|}
\hline \multirow{2}{*}{$\begin{array}{l}\text { Doses de } \mathbf{P} \\
\mathrm{mg} / \mathrm{kg}\end{array}$} & \multicolumn{2}{|c|}{ Colonização micorrízica } & \multicolumn{2}{|c|}{ Número de esporos } & \multicolumn{2}{|c|}{ Número de nódulos } \\
\hline & In & $\mathrm{Ni}$ & In & $\mathrm{Ni}$ & In & $\mathrm{Ni}$ \\
\hline & \multicolumn{2}{|c|}{----------- \% ----------- } & \multicolumn{2}{|c|}{-------- n./50 ml-------- } & \multicolumn{2}{|c|}{------ n\%/planta ${ }^{-1}$------ } \\
\hline 0 & $55,1 \mathrm{a}$ & $0 \mathrm{~b}$ & $169,7 \mathrm{a}$ & $0 \mathrm{~b}$ & $2,8 \mathrm{a}$ & $3,7 \mathrm{a}$ \\
\hline 50 & $40,2 \mathrm{a}$ & $0 \mathrm{~b}$ & $182,7 \mathrm{a}$ & $0 \mathrm{~b}$ & $3,9 \mathrm{a}$ & $2,3 \mathrm{a}$ \\
\hline 100 & $51,3 \mathrm{a}$ & $0 \mathrm{~b}$ & $703,0 \mathrm{a}$ & $0 \mathrm{~b}$ & $6,9 \mathrm{a}$ & $3,4 \mathrm{~b}$ \\
\hline 500 & $47,0 \mathrm{a}$ & $0 \mathrm{~b}$ & $385,7 \mathrm{a}$ & $0 \mathrm{~b}$ & $6,2 \mathrm{a}$ & $5,5 \mathrm{a}$ \\
\hline 1000 & $43,8 \mathrm{a}$ & $0 \mathrm{~b}$ & $409,8 \mathrm{a}$ & $0 \mathrm{~b}$ & $10,8 \mathrm{a}$ & $5,9 \mathrm{~b}$ \\
\hline $\mathrm{R}^{2}$ & - & - & - & - & 0,76 & 0,73 \\
\hline Ajuste & Sem ajuste & Sem ajuste & Sem ajuste & Sem ajuste & Linear $* *$ & Linear $* *$ \\
\hline
\end{tabular}


Tabela 3. Teores de N, P, K, Ca e Mg na parte aérea de Mimosa artemisiana inoculadas (In) ou não inoculadas (Ni) com Glomus etunicatum aos 140 dias após a germinação (Média de 6 repetições).

\begin{tabular}{|c|c|c|c|c|c|c|c|c|c|c|}
\hline \multirow{2}{*}{$\begin{array}{l}\text { Doses de P } \\
\mathrm{mg} / \mathrm{kg}\end{array}$} & \multicolumn{2}{|r|}{$\mathrm{N}$} & \multicolumn{2}{|c|}{$\mathrm{P}$} & \multicolumn{2}{|c|}{$\mathrm{K}$} & \multicolumn{2}{|c|}{$\mathrm{Ca}$} & \multicolumn{2}{|c|}{$\mathrm{Mg}$} \\
\hline & In & $\mathrm{Ni}$ & In & $\mathrm{Ni}$ & In & $\mathrm{Ni}$ & In & $\mathrm{Ni}$ & In & $\mathrm{Ni}$ \\
\hline 0 & $2.96 \mathrm{a}$ & $2.58 \mathrm{~b}$ & $1.97 \mathrm{~b}$ & $2,95 \mathrm{a}$ & $9.47 \mathrm{a}$ & $4.83 \mathrm{~b}$ & $17.03 \mathrm{a}$ & $15,80 \mathrm{a}$ & $3,28 \mathrm{a}$ & $3.37 \mathrm{a}$ \\
\hline 50 & $2,95 \mathrm{a}$ & $2,51 \mathrm{~b}$ & $2,18 \mathrm{~b}$ & $2,77 \mathrm{a}$ & $8,50 \mathrm{a}$ & $6,00 \mathrm{~b}$ & $16,22 \mathrm{a}$ & $18,58 \mathrm{a}$ & $3,62 \mathrm{a}$ & $3,37 \mathrm{a}$ \\
\hline 100 & $3,21 \mathrm{a}$ & $2,86 \mathrm{~b}$ & $2,18 \mathrm{a}$ & $2,28 \mathrm{a}$ & $8,67 \mathrm{a}$ & $5,17 \mathrm{~b}$ & $16,48 \mathrm{a}$ & $15,32 \mathrm{a}$ & $3,48 \mathrm{a}$ & $3,00 \mathrm{a}$ \\
\hline 500 & $3,06 \mathrm{a}$ & $2,90 \mathrm{a}$ & $3,45 \mathrm{a}$ & $2,83 \mathrm{~b}$ & $8,83 \mathrm{a}$ & $7,00 \mathrm{~b}$ & $12,95 \mathrm{~b}$ & $17,58 \mathrm{a}$ & $3,42 \mathrm{a}$ & $3,07 \mathrm{a}$ \\
\hline 1000 & $2,86 \mathrm{a}$ & $2,63 \mathrm{a}$ & $3,40 \mathrm{a}$ & $2,25 \mathrm{~b}$ & $9,33 \mathrm{a}$ & $8,17 \mathrm{a}$ & $9,90 \mathrm{~b}$ & $17,98 \mathrm{a}$ & $3,25 \mathrm{a}$ & $3,27 \mathrm{a}$ \\
\hline $\mathrm{R}^{2}$ & - & 0,84 & 0,99 & - & & 0,91 & 0,99 & - & - & - \\
\hline Ajuste & $\begin{array}{l}\text { Sem } \\
\text { ajuste }\end{array}$ & $\begin{array}{l}\text { Quadrá- } \\
\text { tico } * *\end{array}$ & $\begin{array}{l}\text { Quadrá- } \\
\text { tico ** }\end{array}$ & $\begin{array}{l}\text { Sem } \\
\text { ajuste }\end{array}$ & $\begin{array}{l}\text { Sem } \\
\text { ajuste }\end{array}$ & Linear ** & Linear $* *$ & $\begin{array}{l}\text { Sem } \\
\text { ajuste }\end{array}$ & $\begin{array}{l}\text { Sem } \\
\text { ajuste }\end{array}$ & $\begin{array}{l}\text { Sem } \\
\text { ajuste }\end{array}$ \\
\hline
\end{tabular}

Médias seguidas de mesma letra na linha, dentro de cada dose de P não diferem entre si por Tukey 5\%. Ajuste de regressão significativo *,** a 5 e $1 \%$, respectivamente.

Espécies de sementes grandes podem ter comportamento inverso, ou seja, não dependem muito da simbiose nas fases iniciais de crescimento, quando usufruem das reservas das sementes e têm maior dependência quando estas reservas se esgotam. No caso da Mimosa artemisiana, o sistema radicular pode se tornar mais eficiente com a idade, tornando-a menos dependente da associação.

Os dados da massa da parte aérea seca das mudas com 110 dias indicam que a Mimosa artemisiana é uma planta de dependência micorrízica intermediária, deixando de responder a inoculação quando o nível de P no solo é alto.
O ponto $\mathrm{T}^{\prime}(825 \mathrm{mg} / \mathrm{kg})$ corresponde a aproximadamente $187 \mathrm{mg}$ de $\mathrm{P}$ disponível no solo pela estimativa da Figura 2. Isto parece ser um comportamento comum entre plantas pioneiras de rápido crescimento.

Flores Aylas et al., (2003), estudando o comportamento de espécies arbóreas pioneiras (trema, fedegoso, mutamba, aroeira, cássia verugosa e gravitinga) inoculadas com Glomus etunicatum em três níveis de $\mathrm{P}$ disponível no solo, verificaram que nenhuma delas responderam à inoculação com suprimento adequado de $\mathrm{P}$ (0,2 mg/L de solução do solo). 
CONCLUSÕES

Mimosa

artemisiana

apresenta

dependência micorrízica intermediária

deixando de responder à inoculação quando

\section{REFERÊNCIAS}

ALVAREZ, V. V. H; NOVAIS, R.F; DIAS,

L.E; OLIVEIRA, J.A. Determinação do

fósforo remanescente. Universidade

Federal de Viçosa - MG, 1983.

FERREIRA, D, F. Sistema de análise estatística para dados balanceados. Lavras: UFLA/DEX/SISVAR, 145P, 1998.

FLORES-AYLAS W. W.; SAGGIN, O. J; SIQUEIRA, J. O.; DAVIDE, C. A. Efeito de Glomus etunicatum e fósforo no crescimento inicial de espécies arbóreas em semeadura direta. Pesquisa Agropecuária Brasileira, v.38, 2003.

GERDEMANN, J. W.; NICOLSON, T. H. Spores of mycorrhizal Endogone species extracted from soil by wet sieving and decanting. Transactions of the British Mycological Society, Cambridge, v. 46, p. 235-244, 1963.

GIOVANETTI, M.; MOSSE, B. Na evaluation of techniques for measuring VA mycorrhizal infection in roots. The New o P disponível no solo for maior que 187 $\mathrm{mg} / \mathrm{kg}^{-1}$.

A maior resposta à inoculação de Glomus etunicatum é observada com um $\mathrm{P}$ disponível no solo estimado em $56 \mathrm{mg} / \mathrm{kg}^{-1}$.

Phytologist, Oxford, v. 84, p. 489-500, 1980.

GRACE, C.; STRIBLEY, D. P. A safer procedure for roution staining of vesiculararbuscular mycorrhizal fungi. Mycological Research, Cambridge, v. 95, n. 10, p. 11601162, 1991.

HABTE, M.; MANJUNATH, A. Categories of vesicular-arbuscular mycorrhizal dependency of host species. Mycorrhiza, Heidelberg, v.1, n.1, p.3-12, Sep. 1991.

JANOS, D. P (1980 a). Vesicular arbuscular mycorrhizal affect low-land tropical rain forest plant growth. Ecology, v. 61, p. 151162.

JANOS, D. P. Mycorrhiza applications in tropical forestry: are temperate-zone approaches appropriate? In: NG, F.S.P. Trees and mycorrhiza. Kuala Lumpur: Forest Research Institute, p.133-188, 1988.

JENKINS, W.R. A rapid centrifugalfloration technique for separatin nematodes 
from soil. Plant Dis. Rep. v. 48, p. 692, 1964.

KOSKE, R. E.; GEMMA, J. N. A modified procedure for stining roots to detect VA mycorrhizas. Mycological Research, Cambridge, v. 92, n. 4, p. 486-488, June 1989.

MOREIRA, F. S.; SIQUEIRA, J. O. Microbiologia e bioquímica do solo. Lavras, Editora UFLA, 626 p, 2002.

NEWMAN, E. E. J. A method of estimating the total lenght of root sample. Journal of Applied Ecology, Oxford, v.3, p.139-45, 1966.

SAGGIN JÚNIOR, O. J.; SIQUEIRA, J. O. Avaliação da eficiência simbiótica de fungos endomicorrízicos para o cafeeiro. Revista brasileira de Ciência do Solo, Campinas, v.19, n.2, p.221-228, maio/ago. 1994.

SAGGIN JÚNIOR, O. J.; SIQUEIRA, J. O. Micorrizas arbusculares em cafeeiro. In: SIQUEIRA, J. O. Avanços em fundamentos e aplicação de micorrizas. Lavras: UFLA, 1997.

SAGGIN JÚNIOR, O. J.; SIQUEIRA, J. O; GUIMARÃES，P. T. G.; OLIVEIRA，E. Interação fungos micorrízicos versus superfosfato e seus efeitos no crescimento e teores de nutrientes do cafeeiro em solo não fumigado. Rev. Bras. de Ciên. do Solo, Campinas, v.18, n.1, p.27-36, jan/abr. 1994.

SILVA, F. C. Manual de análises químicas de solos, plantas e fertilizantes. Brasília: Embrapa Solos, Embrapa Informática Agropecuária, 1999.

SIQUEIRA, J.O.; SAGGIN JÚNIOR, O. J. Dependency on arbuscular mycorrhizal fungi and responsiveness of some Brazilian native woody species. Mycorrhiza 11: 245-255, 2001.

VICENT, J.M. A manual for the practical study of root-nodule bacteria. Oxford Blackwell scientific publications, Oxford, $164 p, 1970$. 